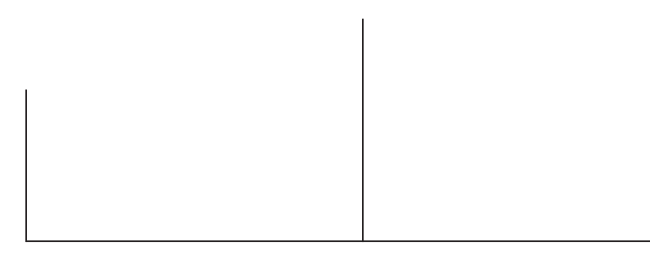

Rev. Latinoam. Psicopat. Fund., II, 2, 108-120

\title{
O papel da recusa nas relações entre o narcisismo e a perversão
}

\author{
Emilse Terezinha Naves
}

O presente artigo pretende discutir as relações existentes entre narcisismo e organização sexual perversa e, nessa articulação, entender também qual é o papel do mecanismo da recusa no desenvolvimento da referida relação.

A recusa da percepção da castração leva o indivíduo a uma recusa de se reconhecer marcado pela falta, que é vista como uma ferida narcisista insuportável. Isto demandaria, de um lado, reforçar as defesas narcísicas e, de outro, buscar relações infiltradas de núcleos perversos. Esse funcionamento levará, conseqüentemente, a uma cisão do ego, o que nos indica uma vulnerabilidade à psicose. $O$ paciente situa-se entre os limites de uma perversão e de uma psicose, e sob determinadas condições uma ou outra organização é privilegiada.

A apresentação de fragmentos de um caso clínico pretende contribuir para a compreensão mais ampliada da questão proposta.

Palavras-chave: Narcisismo, perversão, recusa, psicanálise. 


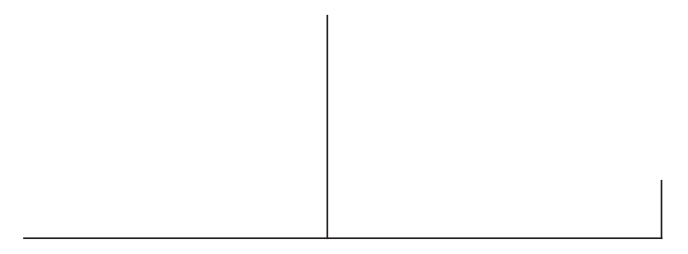

Constata-se na prática clínica uma demanda significativa de pacientes que trazem em sua dinâmica psicopatológica problemas no desenvolvimento da sexualidade. Desde Freud, sabe-se que a sexualidade tem uma participação central tanto na estruturação como no desenvolvimento dos transtornos mentais. No entanto, percebe-se que atualmente há especificidades na organização dessa sexualidade que denotam, de um lado, um culto pela imagem, pelo efêmero, pelo virtual e, de outro, um uso perverso dos objetos, o que indica a primazia da pulsão na organização dessa sexualidade.

Esses elementos constitutivos da sexualidade são encontrados tanto na vida cotidiana como em consultórios, o que nos permite pensar sobre a natureza e funções da organização sexual perversa e do narcisismo. Tratam-se, para várias escolas psicanalíticas, de conceitos complexos e controvertidos. O presente trabalho visa lançar algumas questões que possam auxiliar na elucidação do problema da dimensão narcísica da perversão, ainda que não se tenha a pretensão de esgotar o assunto, amplo demais para ser abarcado por um único artigo.

Existe uma articulação necessária entre narcisismo e perversão? Nessa relação, qual é o papel desempenhado pela dialética do reconhecimento e do desconhecimento da castração? De um modo geral, observa-se a freqüente necessidade que determinados indivíduos possuem de neutralizar e impedir, através da ameaça ou da sedução, qualquer possibilidade de vínculo objetal, o que os leva a atacar permanentemente esses objetos. Para se preservar, sentem que é necessário afrontar, desonrar e controlar o outro. Há uma tentativa de destruir as diferenças, de impedir que os objetos se consolidem como um ser distinto e que possuem desejos próprios. Existe o desejo de tomar posse do objeto, desenvolvendo com ele uma relação fusional. Seria a perversão um caminho encontrado para consumar essa aspiração? Ou melhor, poderia ser a perversão uma defesa estruturada contra uma angústia narcísica? Se for este o caso, qual é o lugar ocupado pelo mecanismo da recusa no desenvolvimento de um narcisismo perverso? Ou poderíamos falar de uma perversão narcísica? 
Para desenvolver essas questões recorro a um caso clínico que vem alicerçando a construção do que pretendo compreender, apresentando a seguir alguns fragmentos do referido caso.

Antônio chegou à psicoterapia após completar trinta e quatro anos de idade. Apresentou-se à primeira entrevista com uma péssima aparência pessoal. Estava mal vestido, com a higiene pessoal bastante descuidada e parecendo estar há dias sem tomar banho. Trazia consigo jornais velhos cuidadosamente guardados em um saco plástico. No momento em que começou a falar, surgiu uma impressão oposta, pois percebi que, apesar de parecer um indigente, apresentava uma capacidade de comunicação bastante eficiente, desenvolvendo suas idéias de forma clara e inteligente, usando um vasto vocabulário e uma adequada organização de pensamento.

Procurou atendimento porque estava com dificuldades para dormir e tinha medo de ficar doente ou morrer, deixando evidente em suas queixas um alto nível de angústia. Antônio é solteiro, não tem profissão definida, mas apresenta enorme talento para a área de vendas. Atualmente está envolvido no movimento político, onde ocupa um cargo na diretoria de um pequeno partido. Esse paciente traz uma história de muita privação sócio-econômica. Vem de uma família numerosa, sendo um dos filhos mais novos. Seu pai também não tem profissão definida e é visto de forma bastante negativa, pois nunca deu condições de vida para os filhos. A mãe morreu quando Antônio tinha dezessete anos, assassinada por um de seus filhos, que traz o diagnóstico de esquizofrenia. A partir de então, Antônio começou a apresentar uma total incapacidade para tomar conta de si mesmo; não tinha horário para dormir, comer ou cuidar de sua higiene pessoal. Começou a apresentar comportamentos delinqüientes, sendo expulso de várias escolas. Conseguiu estudar até a $8^{\underline{a}}$ série, porém apresenta um amplo conhecimento geral que, segundo ele, foi adquirido lendo revistas e jornais tirados do lixo.

O desenvolvimento do processo psicoterapêutico foi marcado por fases em que apareciam, de forma intensa, suas atuações. Reagia de maneira agressiva quando precisava cumprir as normas da instituição, tentando sempre ignorá-las. A relação transferencial foi sempre marcada por muita intensidade e ambivalência. Inicialmente tentava passar uma imagem de homem perigoso e capaz das maiores atrocidades. Em uma das sessões, por exemplo, disse: "Depois que você souber como minha mãe morreu, vai ficar tão assustada que não vai mais querer me atender." Eu percebia que sentia um certo prazer em me assustar com suas histórias de violência. Numa sessão, ele relatou detalhadamente como poderia estuprar uma mulher. Em seguida, perguntava: "Está assustada? Ainda vai querer me atender?"

Durante os primeiros meses de psicoterapia, Antônio demonstrava uma grande desconfiança na relação comigo, perguntando se eu não estava gravando suas sessões e se não contaria para meus colegas de trabalho sua história. Sempre chegava atrasado, faltava muito e antes das sessões ligava para confirmar seu atendimento. 


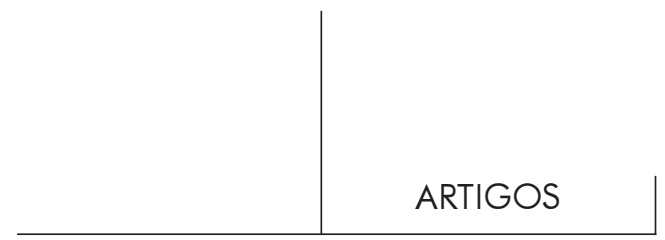

Sua agressividade comigo aumentava quando, na sua fantasia, eu o estava rejeitando. Ele interpretava o contrato terapêutico como uma desconsideração. Não entendia porque eu o atendia sempre no mesmo horário, porque eu não falava sobre mim, porque eu não conversava com ele fora do consultório, enfim, não aceitava os limites do setting, considerando-o como uma desvalorização à sua pessoa.

A sexualidade de Antônio apresenta uma dinâmica complexa. Ele relata que não tem relação sexual genital há aproximadamente dez anos e justifica essa inibição pelo medo da Aids. Diz que sente um grande temor no ato sexual e uma impossibilidade de consumá-lo. Sua atividade sexual consiste no ato masturbatório intenso e constante. Ele é assíduo usuário do sexo por telefone. Vangloria-se por ser um excelente amante, pois, segundo ele, suas "parceiras" gozam com facilidade, já que é "competente na criação de fantasias sexuais". Nas suas fantasias, aparecem componentes sadomasoquistas muito elaborados, mas, na maioria das vezes, ele se coloca como o objeto agredido. Tem a fantasia de ser dominado pela mulher, sendo ela que controla e conduz a relação. Suas fantasias são descritas com detalhes, chegando, às vezes, à beira de um delírio. Apresenta também comportamento voyeurista: costuma observar casais durante o ato sexual (sem a permissão deles) em pequenos hotéis da periferia da cidade.

Apresenta uma transferência altamente erótica e idealizada. Relata com detalhes suas fantasias sexuais em relação à minha pessoa; tenta usar vários tipos de argumentação para me convencer de que é um homem interessante e que seria um parceiro ideal, já que tem um "talento especial para o sexo, além de ser inteligente, crítico e bem informado". Segundo ele, apesar do medo da Aids, teria coragem de ter relações sexuais comigo, porque confia em mim e acredita que eu não o contaminaria.

Apresentei, até aqui, de forma sintética, alguns aspectos que considero importantes para introduzir questionamentos teóricos a respeito do funcionamento pulsional de Antônio. Ainda que não se aprofundem neste artigo as vicissitudes de seu desenvolvimento psicossexual, alguns pontos merecem ser destacados.

O paciente, ao que tudo indica, situa-se no limite entre o masculino e o feminino, o amor e o ódio, entre o medo do objeto e a dependência deste, entre um ordenamento perverso (Bergeret, 1988) e uma psicose, entre o passivo e o ativo. A partir da realidade clínica encontrada, percebe-se que o paciente apresenta uma dinâmica sexual compulsiva em que o outro precisa ser controlado. Ele necessita se apresentar como o detentor do desejo. Seu comportamento está permeado por uma urgente necessidade de supervalorização do Eu e, para alcançar esse intento, ele desconsidera a realidade. A partir desse relato clínico podemos abordar questões fundamentais que orientam este trabalho: o mecanismo da recusa da realidade percebido naquele funcionamento psíquico e, em seguida, a relação entre as perversões e o narcisismo. 


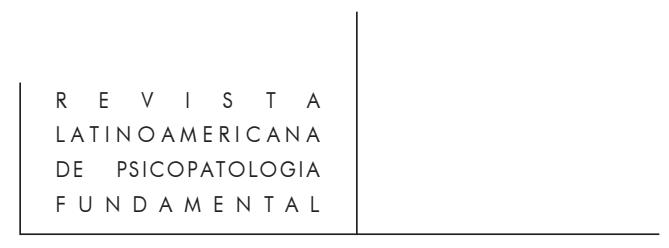

O termo recusa (Verleugnung) é definido por Laplanche e Pontalis (1967) como

modo de defesa que consiste numa recusa pelo indivíduo de reconhecer a realidade de uma percepção traumatizante, essencialmente a da ausência de pênis na mulher.

Freud (1927), em seu artigo sobre o fetichismo descreve, do ponto de vista metapsicológico, o desenvolvimento do mecanismo da recusa e suas consequiências nos processos de clivagem do ego. Esse mecanismo está relacionado às angústias de castração e seria o ponto de partida para o desenvolvimento de uma psicose. Tal defesa propõe a rejeição de uma percepção da realidade a de que as mulheres não possuem pênis e, como consequiência, poderiam ter sido castradas, o que para o menino é uma constatação intolerável, já que o levaria a pensar na possibilidade de sua própria castração.

Sabemos como as crianças reagem às suas primeiras impressões da ausência de um pênis. Rejeitam o fato e acreditam que elas realmente, ainda assim, vêem um pênis. (Freud, 1927)

O mecanismo da recusa desempenha um papel preponderante no desenvolvimento das perversões. No texto "A divisão do ego no processo de defesa", Freud afirma que a criança cria

um substituto para o pênis de que sentia falta nos indivíduos do sexo feminino - o que equivale dizer, um fetiche. Procedendo assim, é verdade que rejeitou a realidade, mas poupou seu próprio pênis. (1938, p. 311)

Esta é uma forma encontrada pela criança de negar os perigos da realidade da ameaça de castração.

É importante notar que nesse mecanismo o paciente não encontra uma resolução definitiva, pois o que foi negado continua presente e exige uma constante renovação. Ele se recusa a perceber a experiência que prova que as mulheres não possuem pênis, no entanto, não conserva a crença de que elas tenham um. No lugar dessa crença, mantém o fetiche que se materializa em um objeto. Vê-se, então, que esse mecanismo se diferencia do recalque, pois a recusa leva a um repúdio da realidade, onde o que é apagado não é a experiência, e sim a lembrança. Na realidade, o indivíduo está certo de que as mulheres não têm pênis, mas através da recusa ele cria um fetiche que lhe assegura a proteção do perigo da castração. Esse processo pode ser claramente ilustrado pela expressão "eu sei... mas mesmo assim", que freqüentemente escutamos dos pacientes e que habilmente foi desenvolvido por Octave Mannoni (1991, p. 189). Essa expressão representa a constituição do mecanismo da recusa. O "mas mesmo assim" é o fetiche, ou seja, apesar de saber perfeitamente que as mulheres não têm o pênis, há recusa em aceitar o fato, mesmo tendo clara a existência dele. 


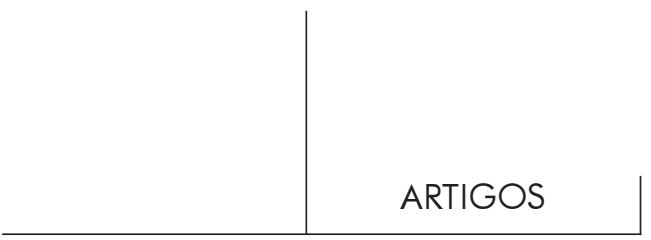

É nesse processo paradoxal de negação, e ao mesmo tempo de reconhecimento da realidade, que o paciente precisa encontrar um substituto, ou seja, um objeto perverso. No entanto, paga-se um alto preço por esse arranjo. E o preço pago por essa solução engenhosa (Freud) é a clivagem do ego. Nesse sentido, podemos considerar a linha tênue que liga as perversões às psicoses. Ou melhor, o indivíduo parece transitar entre uma organização perversa, de um lado, e uma psicose de outro.

A literatura existente confirma a relação do mecanismo patológico da recusa com a castração, com as perversões e seu "parentesco" com as psicoses. No entanto, podemos perguntar qual a articulação entre a recusa e o narcisismo? Em que medida essa defesa nutre o narcisismo do indivíduo? Será que podemos falar de um narcisismo perverso?

Para tanto, retornamos ao caso clínico em alguns de seus fragmentos. Antônio diz: "Ontem eu fiz sexo por telefone. Ela me disse que seu marido não dá prazer pra ela. Aí eu disse: ele não te dá prazer porque ele não toca onde você gosta. Aí fui falando, falando com detalhes e ela gostou tanto que rapidinho chegou ao orgasmo. E enquanto ia falando, eu ia me masturbando." Em uma outra sessão, falando sobre seu medo da relação genital, diz: "Eu não transo porque as mulheres não são dignas de confiança. Elas transam com todo mundo. Quem garante que elas não estão contaminadas pelo vírus da Aids? Prefiro me masturbar do que correr o risco de morrer. Eu preservo muito a minha vida, eu gosto de mim. Mas não vai pensar você que eu não gosto de sexo. Eu tenho uma vida sexual muito ativa, só que faço comigo mesmo ou por telefone. Sei que dou muito prazer às mulheres... Você conhece algum homem que já conseguiu ficar dez anos sem transar para poder preservar a vida? Acredito que não, porque eu sou o único e me sinto especial por gostar tanto da vida. Viu o que você está perdendo, não existe um homem tão puro como eu."

Esses fragmentos clínicos indicam, de um lado, a necessidade do paciente em preservar sentimentos de onipotência, de força, de competência, de suficiência, quando tenta realçar suas qualidades sexuais e, de outro, mostra a angústia suscitada diante de uma relação genital. Para ele, essa relação é sinônimo de morte, de aniquilamento. O que o leva a perceber uma relação genital como tão perigosa? Por que a mulher é considerada por ele como portadora da morte? Ele tem medo de que ela o contamine com o vírus da impotência, do desamparo e da dependência. Para se defender dessa catástrofe psíquica, faz-se necessário construir um Eu grandioso que permita manter a crença na existência do falo. Com isso, perpetua a ilusão de poder e suficiência, juntamente com a negação da dependência e a desvalorização da figura feminina.

As falas de Antônio me sugerem retomar o texto de Freud sobre fetichismo: 


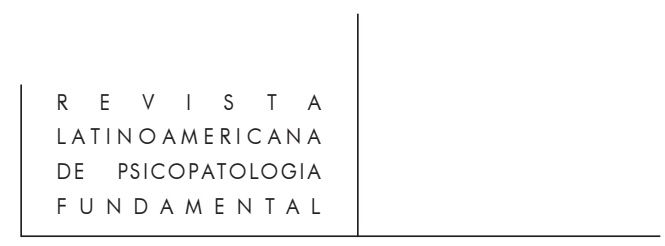

O menino se recusou a tomar conhecimento do fato de ter percebido que a mulher não tem pênis. Não, isso não podia ser verdade, pois se uma mulher tinha sido castrada, então sua própria posse de um pênis estava em perigo, e contra isso ergueu-se em revolta a parte de seu narcisismo que a Natureza, como precaução, vinculou a esse órgão específico. Na vida posterior, um homem adulto talvez possa experimentar um pânico semelhante, quando se eleva o clamor de que o Trono e o Altar correm perigo e conseqüências ilógicas semelhantes decorrerão disso. (1927: p. 180)

De acordo com Bergeret (1991), o indivíduo com uma organização perversa funciona sob dois registros. No primeiro, coloca-se adaptado à realidade, desde que não tenha que lidar com questões pertinentes à representação do sexo feminino. Em um segundo registro, ele desenvolve um modo aberrante e não real para tudo que possa lembrar esta representação. Isto aponta a importância da representação do falo materno para o desenvolvimento psíquico do indivíduo, pois a presença desse, segundo Freud, representa a certeza da presença de si. Assim, parece-nos que essa forma de organização sexual, ou seja, a perversão, está a serviço da manutenção de um estado narcísico. A angústia mobilizada pela castração constitui uma ameaça para a integridade do Eu e, nesse sentido, a negação se torna um eixo em torno da qual, provavelmente, essa autonomia e integridade poderiam ficar asseguradas.

Retomando então o caso clínico, pode-se perguntar: qual é a cena que poderia ser privilegiada em seu funcionamento, sua sexualidade perversa ou seu narcisismo? Ou será que há uma sob a outra? Laplanche, nos seus estudos sobre narcisismo e castração, indica alguns caminhos. Primeiro, ele constata que "a noção de integridade fálica narcísica (a integridade de um todo narcísico que compreende o falo como parte essencial dessa integridade) é inseparável de uma permutabilidade entre o corpo e o seu pênis". Segundo, fala do investimento libidinal que

tem justamente por efeito contrabalançar as tentativas de efração provenientes do exterior. É preciso que a imagem seja carregada, que seja amada para que seja defendida. Teremos que nos perguntar se o que carrega e recarrega a forma narcísica de libido não será justamente, como uma espécie de gerador, a excitação do pênis.

Um terceiro ponto estabelece uma ligação do narcisismo com a angústia de castração, em que afirma que a possibilidade de fragmentação do corpo pode pôr em risco uma perda energética de base. E é na "relação com essa ferida narcísica que se define a angústia de castração.” (1985, p. 73).

Sabemos que a angústia de castração desempenha também um papel primordial no desenvolvimento das perversões, e é como uma defesa contra essa angústia de castração que a recusa se torna patologicamente evidente. Isso fica claro na passagem em que Freud diz: "Em casos bastantes sutis, tanto a rejeição quanto a 


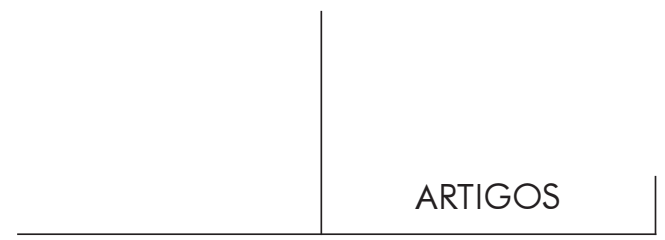

afirmação da castração encontram caminho na construção do próprio fetiche" (1927, p. 184). Um pouco mais tarde ele escreve:

com o auxílio de certos mecanismos, rejeita a realidade e recusa-se a aceitar qualquer proibição: pelo outro, no mesmo alento, reconhece o perigo da realidade, assume o medo desse perigo como um sintoma patológico e subseqüentemente tenta desfazerse do medo... Ambas as partes na disputa obtêm sua cota: permite-se que o instinto conserve sua satisfação e mostra-se um respeito apropriado pela realidade. Mas tudo tem de ser pago de uma maneira ou de outra, e esse sucesso é alcançado ao preço de uma fenda no ego, a qual nunca se cura, mas aumenta à medida que o tempo passa. (1938, p. 309; grifo meu)

Essa ruptura acaba por se constituir, de acordo com Freud, como uma clivagem do ego, e, ao contrário do que se espera, sua natureza integradora "está sujeita a condições particulares e exposta a grande número de distúrbios." (1938, p. 310). Tal brecha seria, ao mesmo tempo, uma ferida narcisista que insiste em sangrar levando o indivíduo a vivenciar tanto a perda de seu valor como um impedimento no reconhecimento do outro, sendo que esse outro só poderá existir à medida que sirva como instrumento de gozo e de satisfação de suas pulsões. Essa satisfação necessita se tornar independente do desejo do outro, pois esse não se mostra como digno de confiança, podendo esgotar o pouco que lhe resta. Há, então, uma necessidade incessante de que o outro esteja a serviço da manutenção de uma fusão primária. Estabelece-se uma luta contra situações de perda e separação, instituindo defesas que levam o sujeito a buscar uma fusão narcísica.

Neste ponto podemos trazer Antônio de volta e pensar em sua cena perversa. O objetivo pulsional é a busca de um gozo permanente, o que dá à sua sexualidade uma qualidade compulsiva. O tema das sessões gira quase sempre em torno de suas fantasias sexuais. A relação transferencial é marcada pela eroticidade e idealização. Há a necessidade de controlar, de se apossar do terapeuta, pois não há espaço para a palavra desse. O terapeuta torna-se o objeto de posse do desejo e por isso não pode falar. Isto pode ser ilustrado com a seguinte passagem: "Eu sei que você tem interesse por mim, só que por causa da ética você não topa. Fica pensando no que poderia acontecer depois, me encontrar no corredor e ficar pensando: meu Deus, como eu fui transar com um paciente, e aí ficar com vergonha de olhar na minha cara. Se for pra te trazer problemas, é melhor parar por aqui. Eu quero te trazer coisas boas, e não te deixar perturbada, então eu deixo a mulher, a fofinha, a gostosinha de lado e só falo com a doutora." Há em sua dinâmica uma associação entre gozo e morte dos objetos e, na intensidade dessa transferência erótica, uma intenção de comunicar sua vida infantil, pois através dela tenta me falar sobre suas angústias mais arcaicas. Transferencialmente, busca viver uma relação diádica, onde necessita se aninhar na mente do terapeuta, pois só assim 


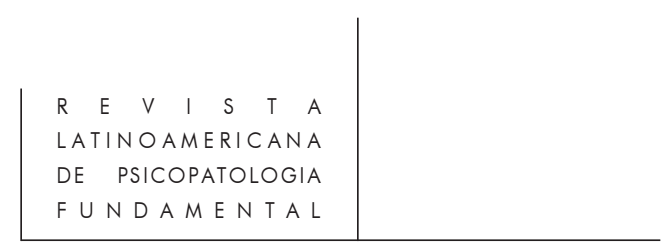

sente-se protegido e livre de suas angústias. Essa transferência possui uma função adesiva, que tenta reconstituir a experiência da união primária mãe-bebê. A erotização da relação transferencial é uma defesa estruturada contra a separação e uma tentativa de fusão narcísica. Além deste aspecto, a transferência erotizada tem também a função de despertar, através da sedução, o desejo da terapeuta, pois só assim poderá se sentir vivo e completo. Dessa forma, ele faz uma tentativa desesperada de sair da sensação de vazio e de fragmentação.

Diante disso, seria imprescíndivel esclarecer o sentido desse funcionamento perverso, já que ele parece se colocar como uma garantia de uma integridade narcísica. E, entre essas duas dinâmicas, não seria a recusa o caminho encontrado para efetuar a ligação entre perversão e narcisismo?

Racamier apresenta a tese da existência de uma perversão narcísica e a situa da seguinte forma:

Clinicamente, a perversão narcísica se caracteriza pela necessidade e o prazer prevalente do indivíduo de se fazer valorizar a si mesmo à custa do outro. É um prazer específico. Certamente ele não é erógeno, mesmo que existam certos aspectos da perversão sexual que sejam com freqüência associados a eles. Este prazer é obtido por manobras e condutas pragmaticamente organizadas, em detrimento das pessoas reais. Quanto às necessidades que ancoram esta perversão, as fontes inconscientes são profundamente contra-depressivos.

Essa organização pressupõe uma tentativa do indivíduo de se constituir como um ser simbólico único e todo poderoso ao abrigo das vicissitudes pulsionais, da ambivalência e do conflito edípico e ainda das separações e dos lutos. (1985, p. 20)

De acordo com alguns autores, a problemática do perverso se caracteriza por não haver uma apreensão da função masculina e feminina, pois o que está sempre presente é a imagem da mãe fálica. Dessa forma, o sujeito funciona em um ideal de ego narcisista, maternal e fálico, sendo que a ferida narcisista encontra-se por trás de qualquer representação objetal. Para Kernberg, há uma agressão pré-genital projetada sobre a mãe, sendo vivenciada como potencialmente perigosa, e esse ódio é estendido ao pai. Assim, pai e mãe são percebidos como uma unidade, criando uma imagem pai-mãe perigosa.

Neste contexto aparece o "trabalho da recusa". A dialética presença-ausência no desenvolvimento da recusa parece apontar dois caminhos: a recusa do objeto como ser separado e ausente e a recusa da percepção da possibilidade da castração. No primeiro caso, prevalece um relacionamento objetal narcisicamente dependente, tendo o Outro apenas a função de garantir a unidade narcisista do indivíduo, acentuando sempre uma necessidade de conservação do Um, de autonomia e dominação. Segundo Green, a recusa do objeto "é uma necessidade vital para o 


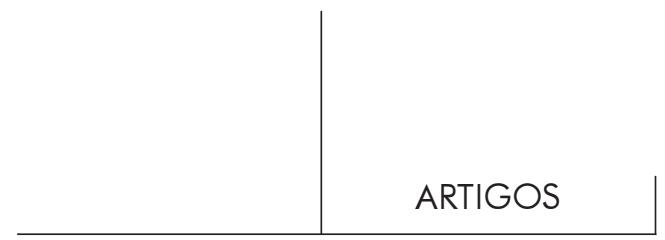

narcisista". Ela é uma garantia de autonomia e consistência para o Eu. Em outras palavras, "a negação não desempenha somente o papel de um recalcamento econômico, mas é a condição para que o Eu consista em alguma coisa." (1988, p. 190). No segundo, a cena perversa predomina, mas o objeto é elevado à condição de fetiche, com o intuito de exercer controle absoluto sobre a figura feminina. Esse fetiche tem a função simbólica de, ao mesmo tempo, reassegurar e desvincular o sujeito do objeto frustrante. Assim, o objeto para o perverso tem que estar presente o tempo todo, mas sob seu total controle, pois só assim sente-se protegido do perigo da castração e da mãe fálica perigosa. A partir dessa ótica, como pode ser pensada a relação entre a recusa da realidade da percepção da ausência de pênis nas mulheres e a recusa do objeto? Nesse sentido, parece haver uma organização narcísica que se liga a certas condições perversas. Estão intimamente ligadas mas, em momentos específicos, uma ou outra condição é privilegiada.

No desenvolvimento da organização subjetiva da criança é fundamental a aceitação da experiência da perda que vai lhe permitir a re-significação da ausência. Se houver a manutenção do mecanismo da recusa da ausência, todo o trabalho de separação será dificultado e, como conseqüência, surgirão transtornos no processo de simbolização, levando o predomínio do ato sobre o pensamento. A dimensão patogênica da recusa produzirá efeitos que deixará o sujeito vulnerável à necessidade incontestável do objeto. No entanto, esse objeto terá apenas a função de atender a sua demanda pulsional.

Citarei agora uma afirmação de Casas de Pereda sobre a patologia da recusa que permite pensar as nuanças existentes entre narcisismo e perversão.

A recusa da castração obstrui o trabalho da repressão; insuficiente diferenciação dos sexos perturba a trama estrutural edípica com certa desarticulação do triangular, onde os lugares perdem a precisão dos contornos e se intercabiam. Isto indica um enfraquecimento da função paterna. As moções incestuosas não conseguem sua delimitação e emergem primazias fálico-narcisistas, desaparecimento de diferenças, limites e normas. (1996, p. 541)

A trama inconsciente de Antônio possibilita uma ampla gama de significações no universo psicopatológico que incita a formular o esclarecimento da questão entre o narcisismo e a sexualidade perversa. Neste caso, a sexualidade perversa desempenha um importante papel para a manutenção da integridade narcísica do sujeito. A recusa é o instrumento que o perverso privilegia para a manutenção de sua valorização narcisista.

Observa-se que o relacionamento objetal narcisista necessita, em determinados casos, fazer uso dos objetos para satisfazer determinadas exigências pulsionais, ou seja, para manter a libido narcisista, o indivíduo necessita se nutrir do objeto através do gozo que dele pode tirar. Há uma necessidade vital de se satisfazer à custa do 


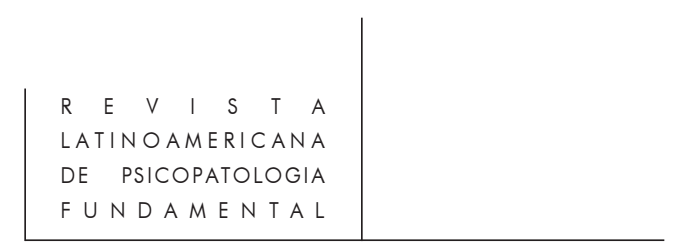

objeto, como uma forma de evitar a angústia da castração. Dessa forma, o objeto passa a ser importante para atender a demanda das pulsões, sendo que essas terão que ser convertidas em um investimento narcisista.

Nesse sentido, o reconhecimento do outro pode significar um esvaziamento de investimentos do Eu, já que leva ao risco da dependência do desejo do outro. Estar na dependência do objeto pode se constituir em um obstáculo no atendimento de sua demanda pulsional. E isso não pode acontecer porque, para manter-se narcisicamente investido, é preciso a posse do objeto sem entraves e sem postergação. Mas para alcançar esse intuito, faz-se necessário desconsiderar a realidade do objeto, levando o sujeito a uma regressão à sexualidade pré-genital, sexualidade essa que está permeada de condições perversas. Assim, há a busca de um objeto parcial, que passa a ser importante apenas para atender ao funcionamento auto-erótico do indivíduo.

Reconhecer o outro é, dialeticamente, reconhecer a ausência deste. O caminho encontrado para negar essa realidade é a recusa da percepção da castração, o que o levaria a uma recusa de se reconhecer marcado pela falta, falta essa que é vista como uma ferida narcísica insuportável. Isto demandaria, de um lado, reforçar as defesas narcísicas e, de outro, buscar relações infiltradas de núcleos perversos. No entanto, esse arranjo levará, conseqüentemente, a uma cisão do ego, o que clinicamente nos faz perceber uma vulnerabilidade à psicose. $\mathrm{O}$ paciente situa-se entre os limites de uma perversão, com fortes características narcísicas, e da psicose. É importante destacar que é em volta do mecanismo da recusa que se efetua essa ligação. Na realidade, ele circula nas duas posições, e, sob determinadas condições, uma se sobrepõe.

Para concluir este artigo, é necessário destacar alguns pontos que poderiam contribuir não apenas para o entendimento teórico das questões acima discorridas, mas também para a evolução da clínica de pacientes com tal organização. É um difícil desafio o trabalho psicanalítico com pacientes que apresentam estruturas tão complexas. Antônio me fez mergulhar nesse mundo complexo e turbulento, onde a angústia se presentifica em cada cena montada no decorrer do trabalho. O ataque ao setting, ao contrato psicoterapêutico, sua recusa em aceitar as diferenças, sua dificuldade no processo de elaboração de uma interpretação, o confrontavam com seus fantasmas e o levavam à possibilidade de encarar a castração. Como consequiência, não podia suportar a dor de reconhecer e aceitar o que não se podia ter. Mas isto parecia tornar-se pesado demais para ele e, a cada vez que se angustiava diante de uma possível elaboração de vivências depressivas, montava um jogo em que sua angústia deveria ser colocada no terapeuta.

Suportar transferencialmente essa dinâmica perversa não é um trabalho fácil. É um desafio, mas talvez não seja impossível. Será preciso percorrer uma longa trajetória teórica e clínica para tanto. 


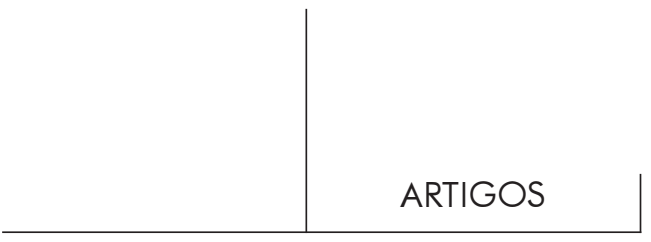

Bibliografia

Bergeret, J. Personalidade - normal e patológica. Porto Alegre, Artes Médicas, 1991.

Casas de Pereda, M. "Recusa, seu efeito estrutural e sua dimensão patogênica". Rev. Bras. de Psicanálise, vol. XXX, 1996, pp. 539-545.

FREUD, S. "Três ensaios sobre a teoria da sexualidade", 1905. ESB., vol. VII. Rio de Janeiro, Imago.

"Leonardo da Vinci e uma lembrança de sua infância", 1910. Op. cit., vol. XI.

"Sobre o narcisismo: uma introdução", 1914. Op. cit., vol. XIV.

"Os instintos e suas vicissitudes", 1915. Op. cit., vol. XIV.

"Fetichismo", 1927. Op. cit., vol. XXI.

“A divisão do ego no processo de defesa”, 1938. Op. cit., vol. XXIII.

Green, A. Narcisismo de vida, narcisismo de morte. São Paulo, Escuta, 1988.

"Abertura para uma discussão sobre a sexualidade na psicanálise

contemporânea”. Rev. Bras. de Psicanálise, vol. XXX, 1996, pp. 565-570.

Hanns, L. Dicionário comentado do alemão de Freud. Rio de Janeiro, Imago, 1996.

Katz, C. S. (org.). Psicose - Uma leitura psicanalítica. São Paulo, Escuta, 1991.

Kernberg, O.F. Agressão nos transtornos de personalidade e nas perversões. Porto Alegre, Artes Médicas, 1995.

Laplanche, J. Castração/Simbolizações. São Paulo, Martins Fontes, 1988.

Vida e morte em psicanálise. Porto Alegre, Artes Médicas, 1985.

"Masoquismo e teoria da sedução generalizada". Jornal de Psicanálise, 26(50): 159-173, 1993.

\& Pontalis, J.B. Vocabulário da psicanálise. São Paulo, Martins Fontes, 1967.

MARUCCO, N.C. "Édipo, castração e fetiche: uma revisão da teoria psicanalítica da sexualidade”. Rev. Bras. de Psicanálise, vol. XXX, 1996, pp. 547-553.

Pommier, G. A ordem sexual - Perversão, desejo e gozo. Rio de Janeiro, Zahar, 1992.

RACAMIER, P. "De la perversion narcissique", 1985.

\section{Resumos}

El presente artículo pretende poner en discusión las relaciones existentes entre narcisismo y organización sexual perversa y, en esa articulación, comprender cuál es el papel del mecanismo de la renegación en el desarrollo de la mencionada relación.

La renegación a la percepción de la castración lleva el individuo a una renegación a reconocerse marcado por la falta, vista como una herida narcisista insoportable. Esto exigiría, por un lado, reforzar las defensas narcísicas y, por otro, buscar relaciones infiltradas por núcleos perversos. Ese funcionamiento llevará, consecuentemente, a una escisión del yo, lo que nos indica una vulnerabilidad a la psicosis. El paciente se sitúa entre los límites de una perversión y de una psicosis, y bajo determinadas condiciones una u otra organización resulta privilegiada. 


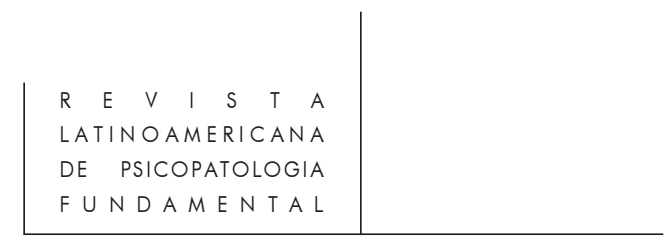

La presentación de fragmentos de un caso clínico pretende contribuir a una comprensión mayor de la cuestión.

Palabras-llave: Narcisismo, perversión, denegación, psicoanálisis.

Cet article prétend discuter les liaisons qui existent entre le narcissisme et l'organisation sexuelle perverse et, de cette forme, comprendre également quel est le rôle du mécanisme de la déni dans le développement de cette liaison.

La déni de la perception de castration conduit l'individu a une déni de se reconnaître assignée pour le manque, qui est vu come une blessure narcissique insupportable. Cela demanderait, d'un côté, renforcer les défenses narcissiques et, de l'autre, chercher des liaisons infiltrées de noyaux pervers. Ce functionnement conduira, par la suite, a une clivage du moi, ce qui nous montre une vulnérabilité à la psychose. Le patient se situe entre les limites d'une perversion et d'une psychose, et sous certains conditions on privilégie l'une ou l'autre organisation.

La présentation de fragments d'un cas clinique prétend contribuer à une compreéntion plus élargie de la question proposée.

Mots-clef: Narcisisme, perversion, deni, psychanalyse.

This paper aims to discuss the ongoing relations between narcisism and perverted sexual organization, and therefore understand what the role of the refusal mechanism in the development of the mentioned relation is.

The refusal of perceiving castration leads the individual to a refusal of recognizing himself as marked by an absence, wich is seen as an unbearable narcisic wound. This requires on one hand to reinforce the narcisic defenses and on the other hand to look for relationships permeated by perverted nuclei. This process will consequently lead to an ego splitting, which shows us a certain vulnerability to psicosis, and under given conditions, one or the other organization prevails.

The presentation of fragments of a clinical case intends to contribute for a broader understanding of the focused issue.

Key words: Narcisism, perversion, refusal, psychoanalysis. 